\title{
"Celebrating old age": an obsolete expression during the COVID-19 pandemic? Medical, social, psychological, and religious consequences of home isolation and loneliness among the elderly
}

\author{
Alexandru Burlacu ${ }^{1,2}$, Ionut Mavrichi ${ }^{3}$, Radu Crisan-Dabija ${ }^{2,4}$, Daniel Jugrin ${ }^{5}, S_{\text {Smaranda Buju }}^{6}$, \\ Bogdan Artene ${ }^{1}$, Adrian Covic ${ }^{2,7,8}$
}

\author{
${ }^{1}$ Department of Interventional Cardiology - Cardiovascular Diseases Institute, Iasi, \\ Romania \\ ${ }^{2 ‘ G r i g o r e ~ T . ~ P o p a ' ~ U n i v e r s i t y ~ o f ~ M e d i c i n e, ~ I a s i, ~ R o m a n i a ~}$ \\ ${ }^{3}$ Sociology Department, Faculty of Theology, University of Bucharest, Bucharest, Romania \\ ${ }^{4}$ Pulmonology Department, Clinic of Pulmonary Diseases, Iasi, Romania \\ ${ }^{5}$ Center for Studies and Interreligious and Intercultural Dialogue, \\ University of Bucharest, Bucharest, Romania \\ ${ }^{6}$ Department of Teacher Training, 'Gh. Asachi' Technical University, Iasi, Romania \\ ${ }^{7}$ Nephrology Clinic, Dialysis, and Renal Transplant Center - 'C.I. Parhon' Hospital, Iasi, \\ Romania \\ ${ }^{8}$ Academy of Romanian Scientists (AOSR)
}

Submitted: 9 May 2020; Accepted: 26 May 2020;

Online publication: 8 June 2020

Arch Med Sci 2021; 17 (2): 285-295

DOI: https://doi.org/10.5114/aoms.2020.95955

Copyright (c) 2020 Termedia \& Banach

\begin{abstract}
Since epidemiological arguments favouring self-isolation during the COVID-19 pandemic are widely recommended, the consequences of social isolation/loneliness of older people considered to be at higher risk for severe illness are neglected. We identified and described medical, social, psychological, and religious issues, indirectly generated by the COVID-19 lockdown. Mortality induced by SARS-CoV-2 and death from other "neglected" issues were put in balance. Arguments for strict lockdown from most European countries are compared with a relaxed approach, as has been applied in Sweden. Social isolation affects disproportionally the elderly, transforming it into a public health concern. One witnesses openly ageist discourse, while painful decisions to prioritising ventilation for younger patients deepens the sense of hopelessness. Fear has led to anxiety disorders and depression. Various religious practices provide resources for coping with isolation/overcoming loneliness. Higher levels of mortality/morbidity due to "COVID-19 versus non-COVID-19" polarisation oblige the healthcare community to find ways to provide proper care for its elders.
\end{abstract}

Key words: COVID-19, older people, geriatric patients, loneliness, social isolation.

\section{Introduction}

"Stay at home if you love yourself" is the motto of the new COVID-19 age [1]. Since epidemiological arguments favouring self-isolation are widely recommended and debated around the world [2], few people are aware of the other (dark) side of the coin: the numerous consequences of social isolation and loneliness of older people [3], who are considered

\author{
Corresponding author: \\ Radu Crisan-Dabija \\ Pulmonology Department \\ Clinic of Pulmonary \\ Diseases \\ 30 Doctor losif \\ Cihac St \\ Iasi 700115, Romania \\ Phone: +400747113426 \\ E-mail: \\ crisanradu@gmail.com
}


to be at higher risk for severe illness [4]. Of note, it is well-recognised and undisputed that loneliness triggers a set of related behavioural and biological processes that correlate to premature death $[5,6]$.

The growing polarisation of "COVID-19 versus non-COVID-19" attitudes and actions is not a new issue and has significant short- and long-term consequences. Almost all modern strategic reaction plans for a viral pandemic have fallen into this dualistic attitude [7, 8]. Medical [9] and non-medical (e.g. economical [10, 11] and ethical [12]) aspects were analysed and explored even in a socalled "worst-case scenario" of this pandemic.

However, it seems fixed in human nature to see and study only the (perceived) most-important issues/risks, neglecting other medical problems that are continuing/growing discreetly in the shade. Simply put, the fight against the growing COVID-19 pandemic seems to hide in a box and put on hold many other health care issues (which unfortunately grow in the "dark" like bad weeds). Well-known pathologies (such as myocardial infarction, cancer, or stroke) have been reported to have lower incidence despite the usually predicted percentage. Other new medical issues seem to rise as a by-product: depression, alcoholism, and suicide [13]. "A fertiliser for other diseases", as loneliness is now defined [14], cannot be put aside, because its consequences may be equal to (in terms of morbi-mortality and costs) those of the pandemic itself.

In an attempt to redefine vulnerability in the era of COVID-19, a recent publication included the elderly into a group "disproportionally exposed to risk" [15]. However, this risk should not be understood as the direct contact of the elderly with the SARS-CoV-2 virus, but mostly as indirect consequences of the social isolation, loneliness, and lack of access to healthcare resources. No guidelines or previously published strategies can cover the needs of vulnerable older people and provide solutions to each of the potential problems. Improvised and hasty healthcare reactions expose the higher-risk category of the elderly to impermissibly high levels of mortality and morbidity.

In this review, we aimed to identify and describe as many aspects as possible (e.g. medical, social, psychological, and religious issues), indirectly generated by the COVID-19 lockdown, which affect both the life and the quality of life of the elderly to the same extent as SARS-CoV-2 itself. Also, we sought to offer one-off solutions to the most pressing problems, which seem to equate to the severity of the pandemic itself.

\section{Elderly mortality during the COVID-19 era - an acute problem}

One must acknowledge that the mortality rate among the elderly with COVID-19 disease has been reported to be higher than 10\% (almost 15\% in people over 80 years old) [16]. Thus, one of the most stringent questions in the press and social media is: "why are elderly people more at risk from coronavirus?" Probably in the future, one will witness precise analyses on how many deaths were directly due to COVID-19 or just associated with an ignored pre-existing pathology in the patient.

As more data is being gathered, healthcare professionals and analysts are faced with the dilemma of discriminating whether patients died "OF" COVID-19 or died "WITH" COVID-19. The risk of death for a patient diagnosed with COVID-19 seems to be significantly associated with the presence of comorbidities [17] and exponentially associated with the number of other diseases such as cardiovascular conditions (primarily coronary artery disease and arterial hypertension), COPD, diabetes, or cancer [18].

Data reporting has not been unitary throughout the world. The "Belgian case" is an excellent example of being "too honest" in reporting COVID-19 deaths [19], overestimating the deaths by labelling COVID-19 death in patients considered suspects, without the chance of being tested or confirmed. Data from many countries have probably been biased by the number of tests performed, with the selection bias being the most important: challenging clinical cases and symptomatic contacts had priority to hospital admissions and tests while the vast majority of asymptomatic cases were left undocumented [20]. It is reasonable to extrapolate and suspect that some of these patients, especially the elderly in remote locations, with low access to medical facilities, may have died during the pandemic and were either missed COVID-19 cases or were counted as COVID-19 deaths within the country's contextual and procedural data collection. Limited testing seems to be the most prominent bias in most countries, as some countries report the number of people tested while others report numbers of tests that could include the same persons tested twice or thrice [21].

More blunt questions arise: are deaths due to SARS-CoV-2 pneumonia or due to lack of access to food and primary healthcare services? A nationwide Italian study correlated the case fatality rate with age and, considering that $23 \%$ of the Italian population is aged 65 and older, this would explain the significant difference in COVID-19 fatality in Italy (7.2\% as of $23^{\text {rd }}$ March) compared with $2.3 \%$ in China (as of $11^{\text {th }}$ February) [22]. Also, the actual figures representing the death tolls might have been biased by the underreporting of the senior care centres' death toll; the World Health Organisation [23] estimates that $50 \%$ of US and Europe deaths attributed to COVID-19 are from long-term care facilities for the elderly [24]. 
Also, ventilators and Personal Protective Equipment (PPE) shortages, although experienced throughout the world, correlated with higher rates of infection and death among both the general population and healthcare workers [25]. Control of the outbreak is subsequently and directly influenced by the availability of PPE for the medical personnel [26].

As healthcare professionals, we are obliged to evoke the ethical implications of quickly attributing all deaths to COVID-19 and to refrain only to epidemiological aspects of mortality and fatality when analysing the number of deaths. It is at least strange to use the mortality attributed to COVID-19 as a measure of both the quality and respect of medical and political institutions from a modern state, regarding its elderly.

As a typical example, one must take into account the myocardial infarction (MI) deaths as COVID-19 monopolised the "scene" of medical activity/resources. "Where have all the STEMIs gone?" is the question of interventional cardiologists all over the globe, reporting a drop of $40 \%$ in Madrid [27] up to $70 \%$ in Lombardy [28]. It seems that while thousands of healthcare professionals fall sick, "the deluge of critically ill COVID-19 patients makes it impossible to triage or test for other underlying conditions" [29]. Thus, shortly, one will probably witness more post-MI angina, reinfarction, heart failure, and arrhythmias. Given the substantial pre-COVID-19 economic burden of heart failure in the elderly [30], the future does not look promising in this regard, and also concerning other chronic diseases such as chronic pulmonary, neurological, psychiatric, metabolic, or systemic diseases.

One global problem that must be taken into account is the future of data reporting and unitary data collection. As established by previously published data, older adults, especially those over 65 , are considered the group with the highest fatality rate [31]. Besides additional social and medical measures that would prioritise these people's access to healthcare, we believe that the epidemiological focus must be concentrated to reduce the undocumented cases of COVID-19 among the elderly in order to reduce the bias in the case fatality rate.

\section{The frailty of older adults - an Achilles heel}

The concept of frailty is not an "all-or-nothing" term, but more of a continuous process, with a blurred line between functional dependence and the "at-risk state" [32]. Elderly functionality or incapacity could be regarded as a dynamic interaction between various states of health (e.g. illnesses, disorders, lesions, traumas) and contextual factors [33]. However, elderly patients are generally divided into subgroups of independent elderly people, frail elderly people, and those too "severely impaired" to be defined as frail [34]. Nevertheless, apart from terminally ill elderly patients, most of the elderly population "suffer" from various degrees of functional dependence, closely associated with frailty.

Care needs arise when one or a combination of disease processes and operational/performance limitations cause temporary or permanent loss of independent function [35]. The health status also determines their primary perceived care needs; for instance, the patients in palliative care have mostly ranked pain or even fear of pain as the most crucial physical need, and anxiety, uncertainty, and security are the primary inner needs [36]. Because this population tends to have a higher prevalence of chronic diseases, physical disabilities [37], mental illnesses, and other comorbidities [33, 38, 39], they have increased necessities to be addressed. Unfortunately, at the extreme, such a high burden led to the (questionable) ethical decision to triage emergencies (COVID-19 or non-COVID-19), requiring multiple hospital resources/ICU.

Besides the health needs and health-related problems, which are difficult or almost impossible to tackle in isolation (shortage of healthcare specialists, the need for medical equipment or tests) [33], there are also the physical, psychological, and social needs to confront $[40,41]$. Basic needs of the (frail) elderly may be systematised into food and nutritional requirements, psycho-emotional concerns (isolation, difficulty in keeping themselves occupied), healthcare system factors (often faulty health insurance system for elderly coupled with accessibility concerns), and financial constraints [42, 43]. All of the mentioned deficiencies, along with the frailty associated with senescence, determine the medical problems and thus have a significant impact on the quality-of-life of the elderly [42, 44].

\section{Sweden's "mirage" - a solution for the elderly?}

Socio-geographic and demographic disparities between countries (e.g. the difference in population age structure) [45], may affect the observed differences in mortality dynamics. Social isolation correlated with a $35 \%$ higher overall mortality rate than those who have social support, with socially isolated people being slightly older [46].

The University of Oxford's COVID-19 Government Response Tracker (OxCGRT) is a tool that provides a systematic way to track the stringency of governments' responses to COVID-19 across countries and time, through a novel index that combines 13 response indicators. Data show that states increase their level of stringency as their 
number of confirmed COVID-19 cases rise, with significant variation in the rate and timing of this relationship [47]. According to OxCGRT, most European countries have established strict suppression measures, including lockdown, while Sweden has chosen milder mitigation strategies, with no lockdown in place, despite similar figures at the start of the outbreak [48].

Concerning the Centre for Disease Prevention and Control statistics, the Swedish death rate per million inhabitants is 233 as of $29^{\text {th }}$ April 2020 , while countries on strict lockdown like Belgium, France, the United Kingdom, Italy, and the Netherlands have higher death rates, with Belgium's rate being 647 as of $29^{\text {th }}$ April 2020 [49]. Additionally, Sweden had a lower excess mortality z-score of 10.79 in the $65+$ age group in week 14 of 2020 than other countries with more severe containment restrictions (Spain - 33.77, England - 31.61, Belgium - 27.42, Netherlands - 25.34, Italy - 23.10, France - 21.76) (https://www.euromomo.eu/graphs-and-maps/), as of $29^{\text {th }}$ April 2020. However, caution must be taken to interpret the data in favour of Sweden's relaxed approach, because recognised demographic differences exist between countries, which could contribute significantly to mortality indicators. For instance, Italy showed significant aging of the population in the last 50 years, although France, Sweden, England \& Wales, Norway, and Denmark did not significantly age in the period [45].

The Nordic countries of Sweden, Norway, and Finland may be considered more similar in terms of socio-economic, political, geographic, and demographic factors; thus, a comparison in their respective outcomes might be less biased. By $28^{\text {th }}$ April 2020, reported COVID-19 deaths in Sweden were 233 per million citizens, whereas Norway reported 38 and Finland 36 per million [49]. A paper estimating the number of infections and the impact of non-pharmaceutical interventions on COVID-19 in 11 European countries showed that the spread of the virus was lowest in Norway $(0.41 \%)$ and much higher in Sweden (3.1\%). However, Italy, Belgium, Spain, and Switzerland had even higher spreading rates $(9.8 \%, 3.7 \%, 15 \%$, and $3.2 \%$, respectively) [50]. Additionally, the study estimated that across 11 countries, since the beginning of the epidemic, 59,000 (21,000$120,000)$ deaths have been averted due to non-pharmaceutical interventions [50]. The conclusion was that one cannot yet deduce whether current interventions had a different impact on controlling the epidemic in Europe.

When assessing the efficacity of various national restraining measures, local particularities must also be taken into account. More than half of all Swedish homes are made up of one resident, the highest proportion in Europe, according to Eu- rostat [51], meaning that Swedes were already used to a certain degree of social distancing. Also, Swedish citizens are generally respectful of public health advice and guidelines [52]. Notably, to date, a third of COVID-19 fatalities have been among older people living in foster care homes, which generated disapproval of citizens towards insufficient governmental measures [53]. Through its tempered measures and subsequent mass immunisation, one can make the case that Sweden could prevent/mitigate a second outbreak, achieving overall better indicators. It is too soon to see an apparent effect of interventions on COVID-19 pandemic control and weigh averted deaths versus the number of deaths to which the measures contributed (due to isolation and negligence of other death causes).

\section{Isolation and elderly care facilities - unsolvable problems to limit deaths}

Europe-wide, a clear consensus on two aspects has emerged: to protect the elderly from acquiring the SARS-CoV-2 and limiting (ICU) hospital admissions. In the seventh update of the Centres for Disease Control and Prevention (CDC) Rapid Risk Assessment, older adults are marked as vulnerable to both infection and severe progression of COVID-19, and also to nosocomial infections after healthcare personnel portage [54].

A particularly vulnerable group of old adults is represented by those institutionalised in elderly care facilities. Nursing homes often concentrate on people with chronic diseases and have an increased risk of control and management of infectious diseases $[55,56]$. As Europe's population is getting older [57], the pressure on all healthcare systems pre-COVID-19 pandemic was to adapt and quickly respond to increasing demands of healthcare services from the elderly [42].

Exactly 1 year before the SARS-COV-2 pandemic struck Italy with hurricane-strength force, Atella, et al. showed that in Italy as well as in all other European countries, adults over 65 years old have at least one chronic condition that needs medical attention, and healthcare services for these people account for $20 \%$ of the total health budget [58].

The burden of chronic diseases and disabilities that often accompany the elderly are now being neglected because of the restrictions emerging partly from the limitations of hospital admissions only for life-threatening conditions, and partly from the restrictions of access to healthcare facilities and general practitioners (GP). In normal conditions, these visits to hospitals or GPs would raise red-flags on possible exacerbations of their chronic condition or the need for additional tests or interventions/changes in their therapeutic schemes [59]. 
While many chronic diseases may be managed ambulatorily, there are several diseases for which the end of pandemic restrictions may already be too far and too late to be managed. For example, chronic obstructive pulmonary disease (COPD) with its exacerbations (considered a geriatric condition per se) was under-diagnosed in older adults [60] even before restricted access to healthcare.

The most common comorbidities of COPD patients include cerebral small-vessel disease, cognitive decline [61], and cardiovascular disease (pre-existing arrhythmias or arterial hypertension, and disease-induced conditions such as cor pulmonale), all these conditions contributing to the extremely high risk of decompensation. Out of a good intention to reduce the risk of infection, the healthcare access limitations of these chronically ill patients, with age-related difficulties to adapt to technology and telemedicine, puts healthcare professionals in the consciously assumed position of facing the apparent consequences of a chronic disease aggravated "beyond repair".

Many scientific proofs state that early diagnosis of various types of cancer results in a higher survival rate [62-64]. Cancer diagnostics still represent a clinical and social challenge driven by the lack of cancer facilities, poor referrals, and delays in scheduling diagnostic tests [65]. The results of social isolation and ambulatory-care limitations during the SARS-COV-2 pandemic may soon result in an increased number of inoperable or late-stage cancer patients or disqualification of some of these patients from a possible surgical cure. When the Centres for Medicare and Medicaid Services (CMS) recommended that "nonessential, elective surgeries and other medical procedures should be postponed during the coronavirus outbreak", the meaning of "essential" seemed to be eclipsed by the COVID-19 issue [66].

If there was no COVID-19, many chronic patients would come to the ER. Unfortunately, the fear of infection causes many patients with symptoms of heart attack, heart failure, or stroke to stay at home and often suffer fatal complications. For example, cardiac arrests occurring at home are striking: for the week from $30^{\text {th }}$ March- $5^{\text {th }}$ April 2020, there were 1990 cardiac arrest calls in New York City, four times as many as the same period a year earlier; and of those, 1429 could not be revived, an eight-fold increase over 2019 [67]. "The same is true for appendicitis and stroke.” [68]. Most likely, people are afraid to go to the hospital and die at home.

Kidney-transplant recipients appear to be at particularly high risk for critical COVID-19 due to chronic immunosuppression and coexisting conditions [69]. Moreover, a very recent correspondence reported mortality of almost $30 \%$ in elderly patients receiving a kidney transplant [70]. Conse- quently, the American Society of Transplantation and the American Society of Transplant Surgeons suggested a phased approach to decreasing transplant activity depending on risk assessment, hospital capacity, and degree of regional virus activity [71]. While recognising the importance of kidney transplants for dialysis patients, one cannot ignore the potential safety issues during this pandemic [72]. Complicating the situation even more, exposing patients to higher SARS-CoV-2 infection risk by requiring frequent transportation to dialysis facilities could be compared to the particular risk of transplantation [73].

A final considerable aspect is the post-pandemic financial impact on healthcare systems as many manageable chronic diseases may present aggravated exacerbations that will result in prolonged hospitalisation and higher treatment costs with reserved clinical outcomes in some cases [74].

\section{Telemedicine for elderly care}

During the COVID-19 pandemic, technology plays a significant role in meeting the population's social, psychological, and religious needs. Telemedicine might meet the elderly's needs for disease (particularly chronic pathologies - see above) management in isolation. In elderly people's home settings, numerous research projects for innovative wearable technologies are currently used [75]. Wrist-worn units with GPS trackers have been proposed for automatic detection of dangers and handling emergency calls [76], automatic detection of falls [77], and cardiac emergencies [78].

Wearables for recognition of unknown diseases have also been described [78], as well as for monitoring known conditions of the cardiovascular system, respiratory system, and diabetes mellitus [79] and surveillance of therapeutic interventions [80]. Telehealth services focusing on social inclusion have been described for the elderly, mainly through the use of videoconferencing [81], with a possible high impact in the context of legislative measures requiring isolation.

Although studies suggest positive clinical benefits of telemedicine use for care of the elderly $[82,83]$, services based on these technologies barely overcome the level of research projects. The fact might be explained by legal, ethical, design, accessibility, and usability concerns that have to be rigorously solved, before extensive deployment [84]. Service design must take into account that seniors are not entirely familiar with technology; some do not have Internet access and, especially cognitively impaired/frail elderly people, have difficulties in using the necessary equipment. Also, medical staff are not always comfortable with using and keeping up with the ever-changing computer-based applications and technologies [84]. 
Studies have shown that patients were most satisfied with home care via telehealth systems, but they would instead use a combination of telecare with conventional medical approaches that imply the presence of the 'warm hands' of medical professionals [84]. Nevertheless, the epidemiologic context and the stringency of isolation measures are barriers for the necessary human touch. Notably, a three-phase interactional model of social presence to make the virtual other "real" through generating another actual user's "there"ness in a virtual environment was proposed [85]. Although built on complex concepts and only at inception, this powerful idea could be an excellent approach for tackling imposed social isolation.

\section{Sociological aspects regarding the impact of the COVID-19 pandemic on the elderly}

This pandemic is a socially lived disease, on multiple layers, ranging from outward structurally imposed social isolation to inward psychological reverberations. Because self-isolation is one of the main recommendations during the COVID-19 pandemic, being adopted as social policy by the vast majority of affected countries, this raises the question of whether it should be treated in its documented consequences as a private matter or societal problem.

Socially isolated people are positively correlated with lower levels of well-being [86]. The general function of social relations has been theorised in terms of social integration, personal identity and validation, affect regulation, and coping mechanisms through mutual assistance. Social inclusion is based on the existence of qualitative social relations, the coexistence of a social identity next to personal status [86], born and shaped through socialisation - a process through which the individual becomes both an object and subject of society.

From a functionalist perspective, social isolation is a form of social exclusion, directly affecting the well-being of individuals and eroding social cohesion. It cannot thus be labelled as a private problem, but rather as a public issue [86]. The consequences are more complicated [87] when vulnerable categories are involved, such as elderly and frail people.

Social isolation is the outward, objective aspect of loneliness. In person-centred, psychodynamic models, loneliness is generated by the internalisation of youth experiences. Sociology sees it as the product of social influences [86]. This latter perspective sheds the sense of responsibility for imposing self-isolation measures as a source of sufferance. Indeed, loneliness can be considered as social pain - not only metaphorically - because MRI examinations show brain activation in the same region when experiencing pain or rejection
[6]. Social isolation affects disproportionally the elderly, transforming it into a serious public health concern [88]; the degenerative pathway generated by it, both in terms of quality of life and social capital, should lead to the development of social gerontology strategies.

The current COVID-19 pandemic has witnessed openly ageist discourses [89] in mainstream media, which further complicates its social experience for the elderly. Suggestions not to panic because the disease mainly affects older people raise the ethical problem of life value.

Painful decisions to prioritise ventilation for younger patients when intensive care unit beds or ventilators are limited deepened the sense of anxiety and hopelessness, although the field of gerontology long advocated for alternatives to chronological age in the treatment choice [90]. Another topic of ageism is the general discussion about the "grey tsunami" - the pressure put on medical systems by the growing elderly cohort in developed countries [91].

Finally, the self-isolated elderly suffers from ethical loneliness. It is the inner isolation felt when abandoned by humanity, or those in power compounded by the experience of one's voice or need not being heard [92]. The impact of the COVID-19 pandemic differs depending on the social and economic status of the countries and the scarcity of material and social resources. In low- and middle-income countries, the implications are more profound because the grandparents still have/ play an active role in raising grandchildren; hence, isolation or infestation with SARS-CoV-2 affects the entire family [93]. The issue has practical, immediate consequences because in several countries the schools were officially postponed, the main reason being the "protection" of the elderly, in families where (unlike in Sweden), different generations live together.

\section{Mental health and the paradox of social isolation in older people}

The pandemic affects the mental health of more people than the actual number of infected ones [94], while psychological implications may persist long after the epidemic [95], with a higher prevalence than the pandemic itself. The predominant focus on the pathogen and its biological risk has led to underestimated or partially known psychological and psychiatric effects, both individually and collectively, both in the short and long term $[96,97]$.

Psychological difficulties related to living with chronic conditions, caused or exacerbated by them, bring significant challenges to older people in social and domestic life, self-care, and mobility [98]. The COVID-19 pandemic has caused un- 
balanced psychological problems in various populations. Because the elderly are predominantly the target group of the epidemic, they have undergone enormous pressure, which has added to their existing vulnerabilities. Although the effects of social isolation are distinguished from those of loneliness, efforts to reduce social isolation could be as relevant as lowering mortality [99].

Even if there is ample evidence of negative results due to social isolation and loneliness, on health [100, 101] and mental well-being [102, 103] in the elderly, there is quite extraordinary evidence that public health professionals under nonCOVID-19 conditions assess social isolation [104]. Indirectly, they would instead acknowledge its consequences in terms of physical and mental health.

Social isolation is not merely a condition that leads to health comorbidities. Instead, it is part of a cascade of complex psychosocial factors that interact together to cause adverse health outcomes in older adults: increased mortality [105], increased sensitivity to dementia [6], declining cognition [87], onset of disability [106], depression [107], harmful or risky behavioural habits, and difficulty with activities of daily living. The extent of social isolation effects is comparable to quitting smoking and exceeds many other risk factors for mortality (obesity, physical inactivity) [101].

Fear of COVID-19 has led to various anxiety disorders (concerns, panic attacks, insomnia, fear of death, fear of the unknown, posttraumatic stress) and depressive states, maintained by incessant information about the virus, the number of infections, mortality rates, and insufficient control and treatment measures [88]. Difficulties in receiving medical services or specific psychiatric treatments has led to mental relapses and uncontrollable behaviours (hyperactivity, agitation, and self-harm) [108]. Uncertainty about the possibility of personal infection and death, about the disease of one's family or friends, has heightened dysphoric mental states [109]. Existing psychiatric conditions have evolved into psychotic or paranoid disorders, even leading to suicide [110]. The prevalence and severity of psychological stress under the COVID-19 pandemic continues to be investigated by several countries to guide decision-makers and the public [111, 112], and the measured psychological impact shows a moderate to severe level due to the pandemic [110].

\section{Religious issues of home-isolation among older adults}

Visiting community meetings, parks, neighbourhoods, places of worship, and day centres are the only socialisation channels for most aging adults. With lockdown or quarantine, these activities have become impossible [113]. Loneliness and social isolation have been shown to significantly impact older adults, both physically and emotionally [114]. Also, older people may be adversely affected by the ageist discourses that may imply that "the loss of older life is not as important as the loss of life of other age groups" [115]. Older patients are being denied ventilators and are left to die due to the overwhelming numbers of inpatients, especially those in need of mechanical ventilation. People are not even allowed to organise funeral ceremonies for relatives that have died isolated in COVID-19 facilities. This dramatic situation has significantly induced fear among older people throughout the world [116].

All these are reasons why older adults need more spiritual support than ever in this crisis, and measures taken to cope with the pandemic must take particular account of this need [117]. Religious practices, such as attending church services, practicing daily prayer, and reading spiritual literature, are strategies individuals use to cope with life stressors. Social support from a religious community and the development of a relationship with God are also essential components of coping [118].

Religion may provide a resource that helps in the search for meaning and in overcoming loneliness. Faith in religion offers the individual a philosophy of life and a whole series of attitudes, values, and beliefs that help him/her to interpret and understand him/herself. At the same time, churches provide a sense of social and community integration, highly correlated with a sense of personal well-being. Usually, churches also provide older members with a wide range of social activities, which tend to pull the older person into contact with other people and reduce the possibility of social isolation and loneliness $[119,120]$. During a time of social isolation, there are some ways to help religious older adults make use of their faith to relieve anxiety during this COVID-19 pandemic:

- To spend time meditating, listening to inspirational programs, or reading uplifting literature [121].

- To care for neighbours by meeting their emotional/physical needs - there is no better way to relieve anxiety and reduce social isolation than by reaching out to others in need [121].

- To stay active in the community from home; currently, many organisations - political parties, faith-based groups, non-profit organisations rely on volunteers to deliver care/help for the elderly and frail [122].

\section{Conclusions}

In this paper, we intended to explore the medical, sociological, psychological, and religious 
consequences of social isolation and loneliness in elderly people during the "staying home period" of the COVID-19 pandemic. Seemingly unsolvable medical situations are analysed to find ways to support and protect the lives and improve the quality of life in the geriatric population. We underline that social isolation is a form of social exclusion, directly affecting the well-being of individuals and eroding social cohesion. One cannot label it as a private problem, but rather as a public issue. The current COVID-19 pandemic has witnessed openly ageist discourse with painful ethical decisions that augment anxiety and hopelessness in the growing elderly group. The impermissibly high levels of mortality and morbidity due to the polarising "COVID-19 versus non-COVID-19" medical attitudes obliges the healthcare community to find ways to provide proper care for our elderly members of society.

\section{Acknowledgments}

This study was funded by the Romanian Academy of Medical Sciences and European Regional Development Fund, MySMIS 107124: Funding Contract 2/Axa 1/31.07.2017/107124 SMIS.

\section{Conflict of interest}

The authors declare no conflict of interest.

\section{References}

1. Reporters S. If You Love Yourself Stay At Home, Pastor Adeboye Tells Nigerians As Coronavirus Cases Rise. http://saharareporters.com/2020/04/26/if-you-loveyourself-stay-home-pastor-adeboye-tells-nigerianscoronavirus-cases-rise. Accessed: $27^{\text {th }}$ of April 2020.

2. Prevention CfDCa (2019). Social Distancing, Quarantine, and Isolation. https://www.cdc.gov/coronavirus/ 2019-ncov/prevent-getting-sick/social-distancing. html. Accessed: $27^{\text {th }}$ of April 2020.

3. Aging Nlo (2019). Social isolation, loneliness in older people pose health risks. https://www.nia.nih.gov/ news/social-isolation-loneliness-older-people-posehealth-risks. Accessed: $27^{\text {th }}$ of April 2020.

4. Prevention CfDCa (2019). People Who Are at Higher Risk for Severe Illness. https://www.cdc.gov/coronavirus/2019-ncov/need-extra-precautions/people-athigher-risk.html.

5. Shankar A, Hamer M, McMunn A, Steptoe A. Social isolation and loneliness: relationships with cognitive function during 4 years of follow-up in the English longitudinal study of ageing. Psychosom Med 2013; 75: 161-70.

6. Cacioppo JT, Cacioppo S. Loneliness in the modern age: an evolutionary theory of loneliness (ETL). In: Advances in Experimental Social Psychology. Olson JM (ed). Academic Press 2018; 58: 127-97.

7. Duley MG The next pandemic: anticipating an overwhelmed health care system. Yale J Biol Med 2005; 78: 355-62.

8. Levin PJ, Gebbie EN, Qureshi K. Can the health-care system meet the challenge of pandemic flu? Planning, ethical, and workforce considerations. Public Health Rep 2007; 122: 573-8.

9. NPR. Fauci Estimates That 100,000 To 200,000 Americans Could Die From The Coronavirus. https:// www.npr.org/sections/coronavirus-live-updates/ 2020/03/29/823517467/fauci-estimates-that-100000-to-200-000-americans-could-die-from-the-coronavirus?t=1587994595761. Accessed: 27th of April 2020.

10. Finance H. APR 24 more on accounting \& financial management in worst-case scenario, COVID-19 coronavirus could cost the U.S. billions in medical expenses. https:// www.healthcarefinancenews.com/node/140021. Accessed: $27^{\text {th }}$ of April 2020.

11. McKibbin WJ, Fernando R. The global macroeconomic impacts of COVID-19: seven scenarios. 2020. https:// www.brookings.edu/wp-content/uploads/2020/ 03/20200302 COVID19.pdf

12. Ibc Cib Cib MKБ IC, Comest Comest Comest KOMECT C, International Bioethics $\mathrm{C}$, et al. Statement on COVID-19: ethical considerations from a global perspective. https://unesdoc.unesco.org/ark:/48223/ pf0000373115.

13. Chew NWS, Lee GKH, Tan BYQ, et al. A multinational, multicentre study on the psychological outcomes and associated physical symptoms amongst healthcare workers during COVID-19 outbreak. Brain Behav Immun 2020. doi:10.1016/j.bbi.2020.04.049.

14. Cole SW, Capitanio JP, Chun K, Arevalo JM, Ma J, Cacioppo JT. Myeloid differentiation architecture of leukocyte transcriptome dynamics in perceived social isolation. Proc Natl Acad Sci USA 2015; 112: 15142-7.

15. Redefining vulnerability in the era of COVID-19. Lancet 2020; 395: 1089.

16. Surveillances $V$. The epidemiological characteristics of an outbreak of 2019 novel coronavirus diseases (COVID-19) - China, 2020. China CDC Weekly 2020; 2: 113-22.

17. Guan WJ, Liang WH, Zhao Y, et al. Comorbidity and its impact on 1590 patients with COVID-19 in China: a nationwide analysis. Eur Respir J 2020; 55: 2000547.

18. Richardson S, Hirsch JS, Narasimhan M, et al. Presenting characteristics, comorbidities, and outcomes among 5700 patients hospitalized with COVID-19 in the New York City Area. JAMA 2020; 323: 2052-9.

19. Euronews. Analysis: can we trust Belgium's COVID-19 death statistics? Euronews. https://www.euronews. com/2020/04/22/analysis-can-we-trust-belgium-scovid-19-death-statistics. Accessed: May $17^{\text {th }} 2020$.

20. Li R, Pei S, Chen B, et al. Substantial undocumented infection facilitates the rapid dissemination of novel coronavirus (SARS-CoV-2). Science 2020; 368: 489-93.

21. Data OWi. Coronavirus (COVID-19) Testing. https:// ourworldindata.org/coronavirus-testing. Accessed: May $17^{\text {th }} 2020$.

22. Onder G, Rezza G, Brusaferro S. Case-fatality rate and characteristics of patients dying in relation to COVID-19 in Italy. JAMA 2020; 323: 1775-6.

23. Organization $\mathbf{W H}$. Statement - Invest in the overlooked and unsung: build sustainable people-centred long-term care in the wake of COVID-19. WHO Europe. http://www.euro.who.int/en/media-centre/sections/ statements/2020/statement-invest-in-the-overlooked-and-unsung-build-sustainable-people-centredlong-term-care-in-the-wake-of-covid-19. Accessed: May $17^{\text {th }} 2020$.

24. KFF. State Reporting of Cases and Deaths Due to COVID-19 in Long-Term Care Facilities. https://www. 
kff.org/medicaid/issue-brief/state-reporting-of-casesand-deaths-due-to-covid-19-in-long-term-care-facilities/. Accessed: May $17^{\text {th }} 2020$.

25. Ranney ML, Griffeth V, Jha AK. Critical supply shortages - the need for ventilators and personal protective equipment during the Covid-19 pandemic. N Engl J Med 2020; 382: e41.

26. Wu H, Huang J, Zhang CJP, He Z, Ming WK. Facemask shortage and the novel coronavirus disease (COVID-19) outbreak: reflections on public health measures. EClinicalMedicine 2020; 21: 100329.

27. Rodríguez-Leora O, Cid-Álvarezd B, Ojedae S, et al. Impacto de la pandemia de COVID-19 sobre la actividad asistencial en cardiología intervencionista en España. REC Interv Cardiol 2020; 2: 82-9.

28. Cosentino N, Assanelli E, Merlino L, Mazza M, Bartorelli AL, Marenzi G. An in-hospital pathway for acute coronary syndrome patients during the COVID-19 outbreak: initial experience under real-world suboptimal conditions. Can J Cardiol 2020. doi:10.1016/j. cjca.2020.04.011.

29. Wood S. The Mystery of the Missing STEMIs During the COVID-19 Pandemic. TCTMD. https://www.tctmd. com/news/mystery-missing-stemis-during-covid-19pandemic. Accessed: $27^{\text {th }}$ of April 2020.

30. Lesyuk W, Kriza C, Kolominsky-Rabas P. Cost-of-illness studies in heart failure: a systematic review 20042016. BMC Cardiovasc Disord 2018; 18: 74.

31. Baud D, Qi X, Nielsen-Saines K, Musso D, Pomar L, Favre G. Real estimates of mortality following COVID-19 infection. Lancet Infect Dis 2020. doi:10.1016/S14733099(20)30195-X.

32. Rockwood K, Fox RA, Stolee P, Robertson D, Beattie BL Frailty in elderly people: an evolving concept. Can Med Assoc J 1994; 150: 48995.

33. Lopes MJ, Escoval A, Pereira DG, Pereira CS, Carvalho C, Fonseca C. Evaluation of elderly persons' functionality and care needs. Rev Latino-Am Enfermagem 2013; 21 : 52-60.

34. Winograd $\mathrm{CH}$, Gerety $\mathrm{MB}$, Chung $M$, Goldstein $\mathrm{MK}$, Dominguez Jr F, Vallone R. Screening for frailty: criteria and predictors of outcomes. J Am Geriatr Soc 1991; 39: 778-84.

35. Williams J, Lyons B, Rowland D. Unmet long-term care needs of elderly people in the community: a review of the literature. Home Health Care Serv Q 1997; 16: 93-119.

36. Wijk H, Grimby A. Needs of elderly patients in palliative care. Am J Hosp Palliat Med 2008; 25: 106-11.

37. Afsar B, Siriopol D, Aslan G, et al. The impact of exercise on physical function, cardiovascular outcomes and quality of life in chronic kidney disease patients: a systematic review. Int Urol Nephrol 2018; 50: 885-904.

38. Tsai YF, Yeh SH, Tsai HH. Prevalence and risk factors for depressive symptoms among community-dwelling elders in Taiwan. Int J Geriatr Psychiatry 2005; 20: 1097-102.

39. Marengoni A, Winblad B, Karp A, Fratiglioni L. Prevalence of chronic diseases and multimorbidity among the elderly population in Sweden. Am J Public Health 2008; 98: 1198-200.

40. Wijk H, Grimby A. Needs of elderly patients in palliative care. Am J Hosp Palliat Care 2008; 25: 106-11.

41. Banach M, Penson PE, Fras Z, et al. Brief recommendations on the management of adult patients with familial hypercholesterolemia during the COVID-19 pandemic. Pharmacol Res 2020; 158: 104891.
42. Shrivastava SR, Shrivastava PS, Ramasamy J. Healthcare of elderly: determinants, needs and services. Int J Prev Med 2013; 4: 1224-5.

43. Reiner Z, Hatamipour M, Banach $M$, et al. Statins and the COVID-19 main protease: in silico evidence on direct interaction. Arch Med Sci 2020; 16: 490-6.

44. Azeez S, Ghalib Alhashim Z, Al Otaibi WM, et al. Stateof-the-art tools to identify druggable protein ligand of SARS-CoV-2. Arch Med Sci 2020; 16: 497-507.

45. d'Albis $H$, Collard F. Age groups and the measure of population aging. Demogr Res 2013; 29: 617-40.

46. Banerjee S, Burkholder G, Sana B, Szirony M. Social isolation as a predictor for mortality: implications for COVID-19 prognosis. medRxiv 2020; doi:10.1101/202 0.04.15.20066548.

47. Oxford Uo. Coronavirus government response tracker. https://www.bsg.ox.ac.uk/research/research-projects/ coronavirus-government-response-tracker. Accessed: $28^{\text {th }}$ of April 2020.

48. Gardner JM, Willem L, van der Wijngaart W, Kamerlin SCL, Brusselaers N, Kasson P. Intervention strategies against COVID-19 and their estimated impact on Swedish healthcare capacity. medRxiv doi:10.1101/20 20.04.11.20062133.

49. Worldometers. Reported Cases and Deaths by Country, Territory, or Conveyance. https://www.worldometers. info/coronavirus/\#countries. Accessed: $28^{\text {th }}$ of April 2020.

50. London IC. Report 13: Estimating the number of infections and the impact of non-pharmaceutical interventions on COVID-19 in 11 European countries. https:// spiral.imperial.ac.uk:8443/handle/10044/1/77731. Accessed: $28^{\text {th }}$ of April 2020.

51. EuroStat (2017). Over half of Sweden's households made up of one person. https://ec.europa.eu/eurostat/ web/products-eurostat-news/-/DDN-20170905-1?inheritRedirect=true. Accessed: $27^{\text {th }}$ of April 2020.

52. Conversation T. Coronavirus: why the Nordics are our best bet for comparing strategies. https://theconversation.com/coronavirus-why-the-nordics-are-ourbest-bet-for-comparing-strategies-135344. Accessed: $27^{\text {th }}$ of April 2020.

53. Observer T. Anger in Sweden as elderly pay price for coronavirus strategy. https://www.theguardian.com/ world/2020/apr/19/anger-in-sweden-as-elderly-payprice-for-coronavirus-strategy. Accessed: $27^{\text {th }}$ of April 2020.

54. Eurosurveillance Editorial T. Updated rapid risk assessment from ECDC on coronavirus disease 2019 (COVID-19) pandemic: increased transmission in the EU/EEA and the UK. Euro Surveill 2020; 25 (12). doi: 10.2807/1560-7917.Es.2020.25.12.2003261.

55. Quality AfHRa. Coronavirus Disease 2019 (COVID-19) and Safety of Older Adults. U.S. Department of Health and Human Services. https://psnet.ahrq.gov/primer/ coronavirus-disease-2019-covid-19-and-safety-olderadults. Accessed: $27^{\text {th }}$ of April 2020.

56. Prevention CfDCa (2019). Preparing for COVID-19: Long-term Care Facilities, Nursing Homes. https:// www.cdc.gov/coronavirus/2019-ncov/hcp/long-termcare.html?CDC_AA_refVal=https $\% 3 \mathrm{~A} \% 2 \mathrm{~F} \% 2 \mathrm{Fwww}$. cdc.gov\%2Fcoronavirus\%2F2019-ncov\%2Fhealthcare-facilities $\% 2$ Fprevent-spread-in-long-term-care -facilities.html. Accessed: $27^{\text {th }}$ of April 2020.

57. EuroStat (2019). Population structure and ageing. https://ec.europa.eu/eurostat/statistics-explained/ index.php/Population_structure_and_ageing\#The_ share_of_elderly_people_continues_to_increase.Accessed: $27^{\text {th }}$ of April 2020. 
58. Atella V, Piano Mortari A, Kopinska J, et al. Trends in age-related disease burden and healthcare utilization. Aging Cell 2019; 18: e12861.

59. Benabdelghaffar H, Neffati O, Fenniche S, et al. Clinical profile and treatment of elderly patients hospitalized for acute exacerbation of chronic obstructive pulmonary disease. A comparative study. Eur Respir J 2013; 42 (Suppl 57): P2138

60. Incalzi RA, Scarlata S, Pennazza G, Santonico M, Pedone $C$. Chronic obstructive pulmonary disease in the elderly. Eur J Intern Med 2014; 25: 320-8.

61. Lahousse L, Tiemeier H, Ikram MA, Brusselle GG. Chronic obstructive pulmonary disease and cerebrovascular disease: a comprehensive review. Respir Med 2015; 109: 1371-80.

62. Tsai WC, Kung PT, Wang YH, Kuo WY, Li YH. Influence of the time interval from diagnosis to treatment on survival for early-stage liver cancer. PLoS One 2018; 13: e0199532.

63. Richards MA, Smith P, Ramirez AJ, Fentiman IS, Rubens RD. The influence on survival of delay in the presentation and treatment of symptomatic breast cancer. Br J Cancer 1999; 79: 858-64.

64. Li S, Ma D, Shi HH, Yu KD, Zhang Q. The effect of delayed adjuvant chemotherapy on relapse of triple-negative breast cancer. J Thorac Dis 2018; 10: 2837-41.

65. Gulzar F, Akhtar MS, Sadiq R, Bashir S, Jamil S, Baig $S M$. Identifying the reasons for delayed presentation of Pakistani breast cancer patients at a tertiary care hospital. Cancer Manag Res 2019; 11: 1087-96.

66. Cardiology Dal. CMS Calls For Postponing All Elective Cardiac Tests and Procedures to Aid COVID-19 Containment. https://www.dicardiology.com/article/cms-callspostponing-all-elective-cardiac-tests-and-procedures-aid-covid-19-containment. Accessed: $28^{\text {th }}$ of April 2020

67. Shaw BCaD. Cardiac Arrest Deaths at Home in New York City Have Increased By a Startling 800\%. http://www. ptca.org/news/2020/0408_INCREASED_DEATHS_NYC. html. Accessed: $30^{\text {th }}$ of April 2020

68. McFarling UL. 'Where are all our patients?': Covid phobia is keeping people with serious heart symptoms away from ERs. StatNews. https://www.statnews.com/ 2020/04/23/coronavirus-phobia-keeping-heart-patients-away-from-er/. Accessed: $30^{\text {th }}$ of April 2020.

69. Alberici F, Delbarba E, Manenti C, et al. A single center observational study of the clinical characteristics and short-term outcome of 20 kidney transplant patients admitted for SARS-CoV2 pneumonia. Kidney Int 2020 97: 1083-8.

70. Akalin E, Azzi Y, Bartash R, et al. Covid-19 and kidney transplantation. N Engl J Med 2020. doi:10.1056/ NEJMc2011117.

71. Kumar D, Manuel O, Natori Y, et al. COVID-19: a global transplant perspective on successfully navigating a pandemic. Am J Transplant 2020. doi:10.1111/ ajt. 15876.

72. Martino F, Plebani M, Ronco C. Kidney transplant programmes during the COVID-19 pandemic. Lancet Respir Med 2020; 8: e39.

73. Kliger AS, Silberzweig J. Mitigating risk of COVID-19 in dialysis facilities. Clin J Am Soc Nephrol 2020; 15: 707-9.

74. Health F. The Projected Economic Impact of the COVID-19 Pandemic on the US Healthcare System. https://s3.amazonaws.com/media2.fairhealth.org/ brief/asset/COVID-19\%20-\%20The\%20Projected\%20 Economic\%20Impact\%20of\%20the\%20COVID-19\%20
Pandemic\%20on\%20the\%20US\%20Healthcare\%20 System.pdf. Accessed: $28^{\text {th }}$ of April 2020.

75. Ludwig W, Wolf KH, Duwenkamp C, et al. Health-enabling technologies for the elderly: an overview of services based on a literature review. Comput Methods Programs Biomed 2012; 106: 70-8.

76. Barnes N, Webster S, Mizutani T, Ng J, Buckland M, Reeves A. Liverpool Telecare Pilot: case studies. Inform Prim Care 2006; 14: 197-202.

77. Essen A, Conrick M. New e-service development in the homecare sector: beyond implementing a radical technology. Int J Med Inform 2008; 77: 679-88.

78. Alwan M, Dalal S, Mack D, et al. Impact of monitoring technology in assisted living: outcome pilot. IEEE Trans Inf Technol Biomed 2006; 10: 192-8.

79. Dang S, Ma F, Nedd N, Aguilar EJ, Roos BA. Differential resource utilization benefits with Internet-based care coordination in elderly veterans with chronic diseases associated with high resource utilization. Telemed J E Health 2006; 12: 14-23.

80. Barnason S, Zimmerman L, Nieveen J, Hertzog M. Impact of a telehealth intervention to augment home health care on functional and recovery outcomes of elderly patients undergoing coronary artery bypass grafting. Heart Lung 2006; 35: 225-33.

81. Boulos MN, Rocha A, Martins A, et al. CAALYX: a new generation of location-based services in healthcare. Int J Health Geogr 2007; 6: 9.

82. Brownsell S, Aldred H, Hawley MS. The role of telecare in supporting the needs of elderly people. J Telemed Telecare 2007; 13: 293-7.

83. Barlow J, Singh D, Bayer S, Curry R. A systematic review of the benefits of home telecare for frail elderly people and those with long-term conditions. J Telemed Telecare 2007; 13: 172-9.

84. Botsis T, Hartvigsen G. Current status and future perspectives in telecare for elderly people suffering from chronic diseases. J Telemed Telecare 2008; 14: 195-203.

85. Schultze U, Brooks JAM. An interactional view of social presence: making the virtual other "real". Information Systems Journal 2019; 29: 707-37.

86. Machielse A. Theories on social contacts and social isolation. In: Hortulanus R, Machielse A, Meeuwesen L. Social Isolation in Modern Society. Routledge, New York 2006; 13-36.

87. Cacioppo JT, Hawkley LC. Perceived social isolation and cognition. Trends Cogn Sci 2009; 13: 447-54.

88. Armitage R, Nellums LB. COVID-19 and the consequences of isolating the elderly. Lancet Public Health 2020; 5: e256.

89. Brooke J, Jackson D. Older people and COVID-19: Isolation, risk and ageism. J Clin Nurs 2020. doi:10.1111/ jocn.15274.

90. Le Couteur DG, Anderson RM, Newman AB. COVID-19 through the lens of gerontology. J Gerontol A Biol Sci Med Sci 2020. doi:10.1093/gerona/glaa077.

91. Gullette MM. Ending Ageism, or How Not to Shoot Old People. Rutgers University Press, New Brunswick 2017.

92. Martel J. Ethical Loneliness: The Injustice of Not Being Heard. Columbia University Press, New York 2015.

93. Lloyd-Sherlock P, Ebrahim S, Geffen L, McKee M. Bearing the brunt of covid-19: older people in low and middle income countries. BMJ 2020; 368: m1052.

94. Reardon S Ebola's mental-health wounds linger in Africa. Nature 2015; 519: 13-4.

95. Lee AM, Wong JG, McAlonan GM, et al. Stress and psychological distress among SARS survivors 1 year after the outbreak. Can J Psychiatry 2007; 52: 233-40. 
96. Malta M, Rimoin AW, Strathdee SA. The coronavirus 2019-nCoV epidemic: is hindsight 20/20? EClinicalMedicine 2020; 20: 100289.

97. Tucci V, Moukaddam N, Meadows J, Shah S, Galwankar SC, Kapur GB. The forgotten plague: psychiatric manifestations of Ebola, Zika, and emerging infectious diseases. J Glob Infect Dis 2017; 9: 151-6.

98. Marengoni A, Angleman S, Melis R, et al. Aging with multimorbidity: a systematic review of the literature. Ageing Res Rev 2011; 10: 430-9.

99. Pugh S. The Social World of Older People: Understanding Loneliness and Social Isolation in Later Life (Growing Older). Victor C, Scambler S, Bond J (eds). Open University Press/McGraw Hill Education 2009.

100. Nicholson NR. A review of social isolation: an important but underassessed condition in older adults. J Primary Prev 2012; 33: 137-52.

101. Gray K. A Conceptual Review of Loneliness Across the Adult Life Course (16+ years). University London 2019.

102. Luanaigh CO, Lawlor BA. Loneliness and the health of older people. Int J Geriatr Psychiatry 2008; 23: 1213-21.

103. Kharicha K, Iliffe S, Manthorpe J, et al. What do older people experiencing loneliness think about primary care or community based interventions to reduce loneliness? A qualitative study in England. Health Soc Care Community 2017; 25: 1733-42.

104. Dickens AP, Richards SH, Greaves CJ, Campbell JL. Interventions targeting social isolation in older people: a systematic review. BMC Public Health 2011; 11: 647.

105. Elovainio M, Hakulinen C, Pulkki-Raback L, et al. Contribution of risk factors to excess mortality in isolated and lonely individuals: an analysis of data from the UK Biobank cohort study. Lancet Public Health 2017; 2: e260-6.

106. Abdi S, Spann A, Borilovic J, de Witte L, Hawley M. Understanding the care and support needs of older people: a scoping review and categorisation using the WHO international classification of functioning, disability and health framework (ICF). BMC Geriatrics 2019; 19: 195.

107. Holt-Lunstad J, Smith TB, Layton JB. Social relationships and mortality risk: a meta-analytic review. PLOS Med 2010; 7: e1000316.

108. Yao H, Chen JH, XU YF. Patients with mental health disorders in the COVID-19 epidemic. Lancet Psychiatry 2020; 7: e21.

109. Shigemura J, Ursano RJ, Morganstein JC, Kurosawa M, Benedek DM. Public responses to the novel 2019 coronavirus (2019-nCoV) in Japan: mental health consequences and target populations. Psychiatry Clin Neurosci 2020; 74: 281-2.

110. Wang C, Pan R, Wan X, et al. Immediate psycholog ical responses and associated factors during the initial stage of the 2019 coronavirus disease (COVID-19) epidemic among the general population in China. Int J Environ Res Public Health 2020; 17: 1729.

111. Qiu J, Shen B, Zhao M, Wang Z, Xie B, Xu Y. A nationwide survey of psychological distress among Chinese people in the COVID-19 epidemic: implications and policy recommendations. Gen Psychiatr 2020; 33: e100213.

112. Li W, Yang Y, Liu ZH, et al. Progression of mental health services during the COVID-19 outbreak in China. Int J Biol Sci 2020; 16: 1732-8.

113. Girdhar R, Srivastava V, Sethi S. Managing mental health issues among elderly during COVID-19 pandemic. J Geriatr Care Res 2020; 7: 29-32.
114. Berg-Weger M, Morley JE. Loneliness in old age: an unaddressed health problem. J Nutrition Health Aging 2020; 24: 243-45.

115. Brooke J, Jackson D. Older people and COVID-19: Isolation, risk and ageism. J Clin Nurs 2020. Doi: 10.1111/ jocn.15274.

116. Mehra A, Rani S, Sahoo S, et al. A crisis for elderly with mental disorders: relapse of symptoms due to heightened anxiety due to COVID-19. Asian J Psychiatry 2020; 51: 102114.

117. Statement. Older persons need more support than ever in the age of the Covid-19 pandemic. https:// www.coe.int/en/web/commissioner/view/-/asset publisher/ugj3i6qSEkhZ/content/older-persons-needmore-support-than-ever-in-the-age-of-the-covid-19pandemic. Accessed: 29.04.2020.

118. Harris GM, Allen RS, Dunn L, Parmelee P. "Trouble won't last always": religious coping and meaning in the stress process. Qual Health Res 2013; 23: 773-81.

119. Cox H, Hammonds A. Religiosity, aging, and life satisfaction. J Religion Aging 1989; 5: 1-21.

120. Rote S, Hill TD, Ellison CG. Religious attendance and loneliness in later life. Gerontologist 2013; 53: 39-50.

121. Koenig HG. Ways of protecting religious older adults from the consequences of COVID-19. Am J Geriatric Psychiatry 2020; doi: 10.1016/j.jagp.2020.04.004.

122. Archbald-Pannone L. COVID-19: 4 tips to help the elderly stay connected. https://www.weforum.org/agenda/2020/03/seniors-elderly-coronavirus-isolation/. Accessed: 29.04.2020. 